\title{
Spotlight on scrapie in hunt for sheep BSE
}

\section{Declan Butler}

Britain is to step up its efforts to discover whether bovine spongiform encephalopathy (BSE) is present in the national sheep flock. Some experts fear that the disease may exist in sheep but that it is mistaken for scrapie, which is endemic in the flock.

David King, the government's chief scientific adviser, announced that the government will test thousands of scrapie cases for the agent that causes BSE. The move, which critics say amounts to a reversal in government policy, follows last month's controversy over whether researchers in another experiment had spent five years accidentally testing cow brains instead of sheep brains for BSE (see Nature 413, 760; 2001).

The new project revives a proposal made three years ago to use a cheap technique that distinguishes between strains of prion protein by revealing their conformations and glycosylation patterns. The test takes just 48 hours.

Until now, UK government experiments on BSE in sheep have relied exclusively on conventional strain typing, which discriminates prion strains well but takes two years to complete because it requires analysis of incubation times and lesion profiles in mice inoculated with sheep extracts. As a result, only 180 sheep brains have so far been tested.

King said he was "confident" that the tests will gather a significant amount of data in a

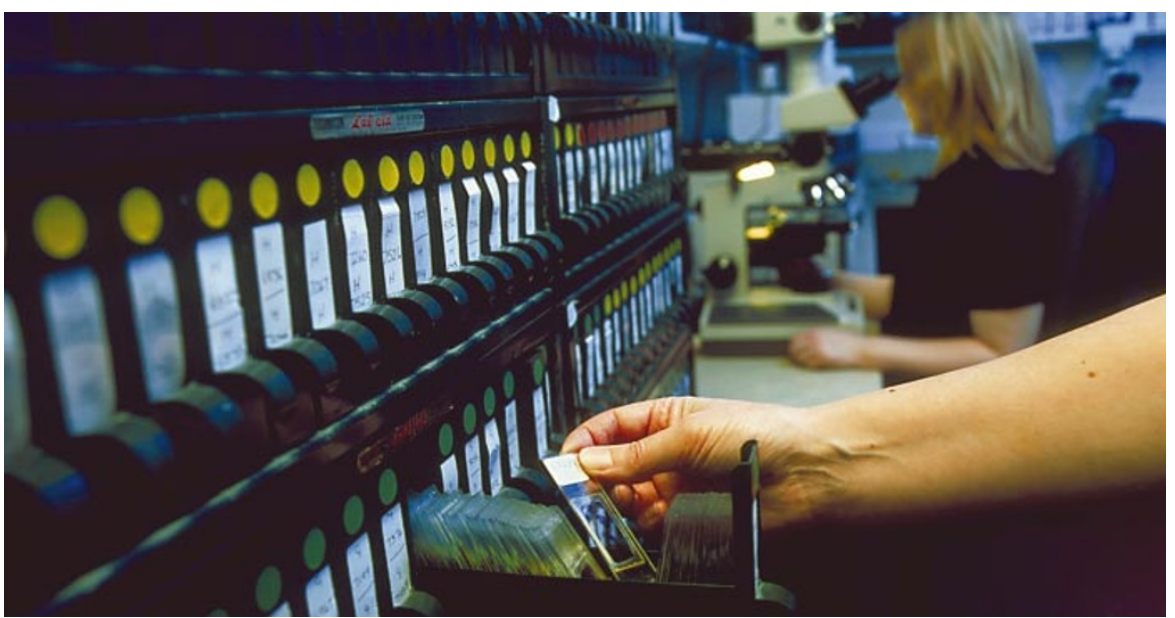

Fast track: rapid testing of brain samples will help to clarify whether Britain's sheep have BSE.

short time. But he added that, because the test was still being validated by the government's Veterinary Laboratory Agency, it would take "months, rather than weeks to be statistically certain that there is no BSE in sheep".

The test to be used was developed in 1996 by John Collinge of Imperial College School of Medicine in London, a member of the UK government's Spongiform Encephalopathy Advisory Committee (SEAC).

But some scientists are sceptical of the test's ability to distinguish scrapie and BSE. For example, a group at the Institute of
Animal Health near Newbury, Berkshire, has reported that one scrapie strain, CH1641, gives a similar glycosylation pattern to BSE.

SEAC nonetheless said in 1999 that glycoform profiling should be a high priority. Collinge complains that the Department for Environment, Food and Rural Affairs (DEFRA) has not used the test enough to improve its distinguishing power. But Oliver Cattermole, a DEFRA spokesman, says that the validation process is time-consuming, and adds that the test is "not the be all and end all" of sheep BSE research.

\section{Middle Eastern promise as synchrotron wins approval}

Quirin Schiermeier, Munich

The scientific commission of the United Nations Educational, Scientific and Cultural Organization (UNESCO) has formally endorsed the creation of a synchrotron radiation facility in the Middle East.

The facility, planned for construction near Amman in Jordan, will operate under the auspices of UNESCO, whose general assembly, currently sitting in Paris, is expected to approve the plan on 3 November.

The International Centre for Synchrotron-light for Experimental Science and Applications for the Middle East, known as SESAME, is a joint project by Armenia, Cyprus, Egypt, Greece, Iran, Israel, Jordan, Morocco, Oman, the Palestinian Authority and Turkey. The idea was born in 1999, when Germany offered to donate its dismantled BESSY I synchrotron to the Middle East.

The agreement with UNESCO is a big step forward for the project. UNESCO will provide the institutional framework for hiring staff and for all contractual arrangements between member states, as it did 50 years ago for CERN, the European particle-physics laboratory in Geneva.

Jordan will pay US\$6million for a new building, and the European Union and the International Atomic Energy Agency have promised to support the installation and modernization of the German synchrotron.

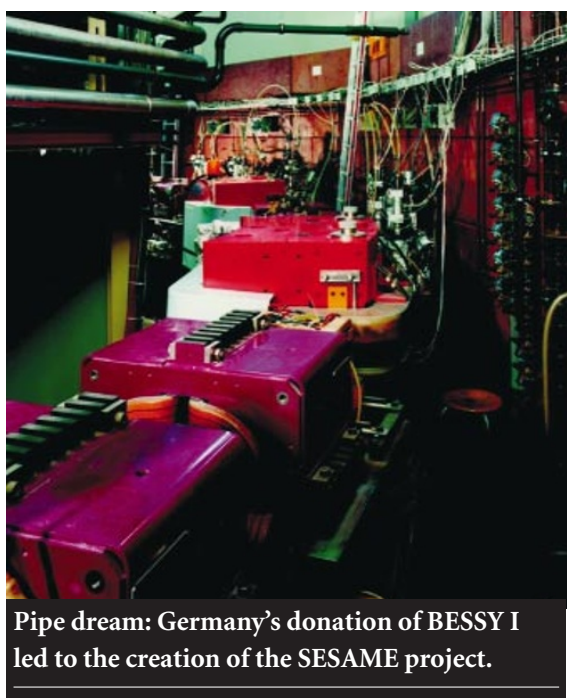

The SESAME member states must cover the rest, including the running costs.

Synchrotrons produce high-quality $\mathrm{X}$ rays by circulating electrons around a ring at high speed. Basic researchers from many disciplines use them to study the molecular structures of organic and inorganic matter.

"In the current political situation, scientific exchange in the Middle East is even more important than before," says Howard Moore, a spokesman for UNESCO's science division. "This will become a stateof-the-art machine," says Dieter Einfeld, technical director of SESAME, who is overseeing the training of 20 scientists from the region to build and operate SESAME.

Operation could begin within as little as three years, says Herwig Schopper, former director general of CERN and head of SESAME's interim council. But the synchrotron must first be shipped to Jordan and upgraded to achieve higher energies and the short wavelengths required for structural biology. The storage ring is to be lengthened to 120 metres in circumference, and equipped with magnets to enhance its performance. 